Nachruf

\title{
George Rosen (1910-1977)
}

Von Erwin H. Ackerknecht

Am 27. Juli 1977 starb an einer Koronarthrombose George Rosen, Yale's Professor der Medizingeschichte, kurz vor Vollendung seines 67. Altersjahres in Oxford, wo er sich zu Studien aufhielt.

Geboren 1910 in Brooklyn, New York, hatte Rosen 1930 das hochgeachtete City College absolviert. Wegen des damaligen Numerus clausus für jüdische Studenten in USA war er genötigt, Medizin in Berlin zu studieren, wo er 1935 mit einer medizinhistorischen Arbeit über Beaumont abschloß (das Thema stammte von Henry E. Sigerist).

1935 brachte Rosen nicht nur sein Doktordiplom heim nach New York, sondern etwas viel Kostbareres, seine junge Frau, Beate Caspari, eine Kollegin und Tochter eines Berliner Arztes, die neben ihrer eigenen Tätigkeit als Ophthalmologe ihrem Mann eine unersetzliche Helferin wurde. Rosen praktizierte bis 1942, sich in ORL spezialisierend. Nebenher studierte er aber noch Soziologie, welche er mit einem Dr.phil. der Columbia University 1944 abschloß. Seine Doktorarbeit, die Geschichte der Spezialisation, leider wegen des Krieges wenig beachtet, ist eines der besten medizinhistorischen Bücher des 20. Jahrhunderts geblieben.

Von 1943-1946 war er mobilisiert, wobei er vor allen Dingen zur Sammlung medizinischer Daten in den USA und Europa verwendet wurde. Von 1946-1952 war er der erste Redaktor des heute noch erscheinenden «Journal of the History of Medicine».

Da Rosens Aussichten akademisch auf dem Gebiet der Medizingeschichte damals gleich Null erschienen, mußte er sich praktisch der öffentlichen Gesundheitspflege, Public Health, zuwenden. 1947 bestand er seinen Master of Public Health. Im Public Health Department der Stadt New York stieg er schnell auf und wurde 1951 als Professor für Public Health Education an die Columbia University berufen. Hier wirkte er bis 1969, wobei er von 1950-1957 noch Associated Medical Director der Gesundheitsversicherung für Groß-New York war und von 1957 an fast bis an sein Lebensende als Herausgeber das hochgeachtete «American Journal of Public Health» leitete. Dabei blieb er medizinhistorisch produktiver als die meisten vollamtlichen Vertreter dieses Faches. 1969 wurde er dann an die Yale-University als Professor für Medizingeschichte und Epidemiologie berufen. 
Rosen hat sich vor allen Dingen mit den sozialen Faktoren in der Medizingeschichte beschäftigt. Er ist derjenige von Sigerists Schülern, der diese Tendenzen des Meisters besonders intensiv gepflegt und weiterentwickelt hat. Kurz vor dem Spezialisierungsbuch erschien (1943) sein ausgezeichnetes Buch über die Krankheiten der Bergarbeiter, kurz nachher (1945) seine Studie über Ärztehonorare. 1958 veröffentlichte er seine immer noch unübertroffene Geschichte der öffentlichen Gesundheitspflege. 1968 gab er mit «Madness in Society» eine Geschichte der Geisteskrankheiten, soziologisch gesehen. 1974 hat er glücklicherweise unter dem Titel «From Medical Police to Social Medicine» ein Dutzend seiner wertvollsten Artikel auf diesem Gebiet, das ja recht eigentlich das seine war, in Buchform herausgebracht. 1975 erschien noch eine Geschichte der Präventivmedizin in den USA 1900-1975. In den letzten Jahren sammelte er Material zur Geschichte der Gesundheit in den modernen Großstädten.

$\mathrm{Zu}$ diesen Büchern kommen noch Hunderte von Artikeln, Buchbesprechungen und Übersetzungen. Es muß festgehalten werden, daß Rosen zwar der Spezialist für Geschichte der öffentlichen Gesundheitspflege war, daß sich aber sein Schaffen und Wissen keineswegs auf dieses Gebiet beschränkte. Seit den «negativen Faktoren in der Medizingeschichte» (1938) hat er immer wieder wertvolle theoretisch-methodologische Beiträge geleistet. Bereits 1946 schrieb er z.B. über die Philosophie der Ideologie und die Entstehung der modernen Medizin in Frankreich, 1951 einen außerordentlich lichtvollen Artikel über den Begriff der romantischen Medizin.

Diese schier unbegreifliche Leistung fand Anerkennung durch zahlreiche Medaillen, Ehrenmitgliedschaften usw. Zur Zeit seines Todes war Rosen Präsident der Internationalen Akademie für Medizingeschichte.

Rosen war eine ausgeglichene, heitere und freundliche Natur. Nie schien er gehetzt; sehr selten war er zornig. Sein Familienleben war von seltener Harmonie (sein Sohn ist pathologischer Anatom, seine Tochter Kunsthistorikerin). 35 Jahre lang war er mir ein treuer und verständnisvoller Freund. Es war gut, mit ihm zu sein. Er war von sehr breiter Bildung und großer Belesenheit, ein begeisterter Buchsammler, ein begabter Sonntagsmaler (die Wahl seiner Illustrationen für das Buch von 1974 bezeugt sein malerisches Verständnis). Es ist typisch für ihn, daß er vor ein paar Jahren sich so für Barockkirchen begeisterte, daß er seine Sommerferien damit verbrachte, Süddeutschland nach denselben abzusuchen. Er war ohne jede provinzielle Borniertheit. Sein Tod ist nicht nur ein schmerzlicher, unersetzlicher Verlust für die Seinen, mit denen wir um ihn trauern, sondern auch für die Medizingeschichte in den USA und in der ganzen Welt. 